\title{
Erratum to: New Minimum Relative Humidity Requirements Are Expected to Lead to More Medical Device Failures
}

\author{
Mehdi Kohani $^{1} \cdot$ Michael Pecht $^{2}$
}

Published online: 4 February 2016

(C) Springer Science+Business Media New York 2016

Erratum to: J Med Syst (2016) 40:58

DOI 10.1007/s10916-015-0421-1

The original version of this article unfortunately contained an error. The published Fig. 2 image was incorrect. The correct version is provided here.

The online version of the original article can be found at http://dx.doi.org/ 10.1007/s10916-015-0421-1.

Michael Pecht

pecht@calce.umd.edu

Mehdi Kohani

mkohani@calce.umd.edu

1 Center for Advanced Life Cycle Engineering (CALCE),

University of Maryland-College Park, 1184 Engineering Lab

Building, College Park, MD 20742, USA

2 Center for Advanced Life Cycle Engineering (CALCE),

University of Maryland-College Park, S1103 Engineering Lab

Building, College Park, MD 20742, USA 


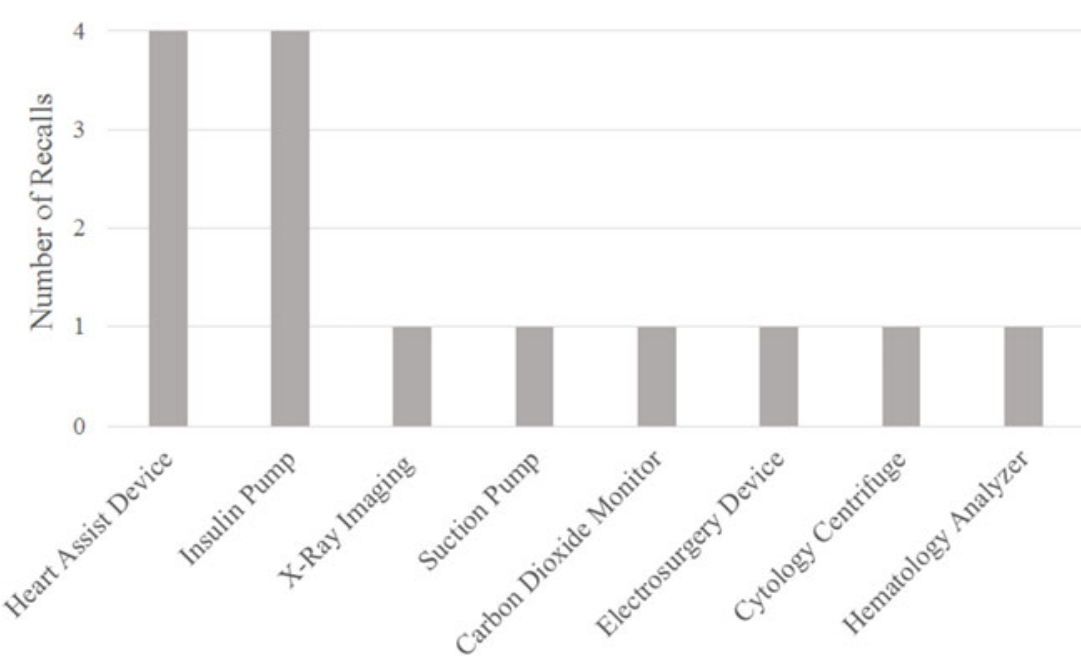

Fig. 2 Distribution of device recalls, according to the FDA's medical device recall database 